\title{
Pengaruh Pelatihan dan Pengembangan SDM terhadap Prestasi Kerja pada PT Tanjung Enim Lestari Pulp and Paper Unit Chemical Plant
}

\author{
M. Rizky Pippo Pratama1) \\ ${ }^{1)}$ PT Waskita Karya \\ Email :rizkypippo98@gmail.com ${ }^{l)}$
}

\begin{abstract}
Abstrak
Penelitian ini bertujuan untuk mengetahui pengaruh pelatihan dan pengembangan sumber daya manusia terhadap prestasi kerja pada PT Tanjung Enim Lestari Unit Chemical Plant. Penelitian ini menggunakan metode penelitian kuantitatif. Penelitian ini melibatkan sebanyak 33 karyawan pada PT Tanjung Enim Lestari Unit Chemical Plant. Sumber data diperoleh melalui data primer dan data sekunder dengan teknik pengumpulan data yang dilakukan melalui observasi dan penyebaran kuesioner kepada seluruh anggota responden. Berdasarkan hasil pengujian hipotesis dengan ketentuan jika thitung $>t_{\text {tabel }}$ maka hipotesis diterima. Berdasarkan hasil penelitian menggunakan SPSS V.19 dapat disimpulkan bahwa terdapat pengaruh yang signifikan antara pelatihan dan pengembaran SDM terhadap prestasi kerja secara parsial. Uji F menjelaskan bahwa terdapat pengaruh yang signifikan antara variabel pelatihan dan pengembangan sdm terhadap prestasi. Hasil uji koefisien determinasi $\left(R^{2}\right)$ menunjukan Adjusted R Square 0,578. Hal ini menjelaskan bahwa 57,8\% variasi variabel prestasi kerja dapat dijelaskan oleh variabel pelatihan dan pengembangan $\mathrm{sdm}$, sisanya 42,2\% dijelaskan oleh variabel lain diluar penelitian.
\end{abstract}

Kata Kunci: pelatihan, pengembangan SDM, prestasi kerja

\section{Pendahuluan}

Menurut Handoko (2012) mengemukakan bahwa manajemen sumber daya manusia adalah pengakuan terhadap pentingnya satuan tenaga kerja organisasi sebagai sumber daya manusia yang vital bagi pencapaian tujuan organisasi dan pemanfaatan berbagai fungsi dan kegiatan personalia untuk menjamin bahwa mereka digunakan secara efektif dan bijak agar bermanfaat bagi individu, organisasi dan masyarakat.

Sunyoto (2012:31) menyatakan bahwa Manajemen sumber daya manusia didefenisikan: Human resource management is the activities under taken to attact, develop, motivate, and maintain a high performing work force within the organization (Manajemen sumber daya manusia adalah aktivitas yang dilakukan merangsang, mengembangkan, memotivasi, dan memelihara kinerja yang tinggi dalam organisasi). Pada dasarnya manusia memiliki potensi dasar dan kemampuan yang idealnya akan terus menerus berkembang apabila diasah secara kontinyu dan berkelanjutan. Membangun karir merupakan salah satu tugas perkembangan yang akan dilalui dalam kehidupan individu yang harus terus meningkatkan kemampuannya agar dapat membangun prestasi yang dimilikinya. Sebaliknya, suatu organisasi juga akan semakin maju dan berkembang apabila sumber daya yang dimiliki oleh karyawannya baik dan berkualitas.

Perusahaan dapat melakukan pelatihan dan pengembangan untuk meningkatkan kualitas perusahaan. Agar prestasi para karyawan lebih baik dan kualitasnya juga membaik untuk mendapatkan prestasi. Dengan kualitas kinerja karyawan yang baik maka karyawan akan semakin ahli dan terampil dalam pekerjaannya. Pelatihan dan pengembangan, juga bertujuan untuk meningkatkan efisiensi tenaga dan waktu. 
Masalah dari penelitian ini adalah apakah pelatihan dan pengembangan sdm berpengaruh secara parsial dan simultan terhadap prestasi kerja karyawaan pada PT. Tanjung Enim Lestari Pulp and Paper Unit Chemical Plant? Adapun tujuan dari penelitian ini adalah untuk mengetahui apakah pelatihan dan pengembangan sdm berpengaruh secara parsial dan simultan terhadap prestasi kerja karyawaan pada PT. Tanjung Enim Lestari Pulp and Paper Unit Chemical Plant.

\section{Hipotesis Penelitian}

Adapun hipotesis pada penelitian ini adalah sebagai berikut :

H1: Diduga adanya Pelatihan berpengaruh terhadap Prestasi Kerja.

H2: Diduga adanya Pengembangan Sumber Daya Manusia berpengaruh terhadap Prestasi Kerja.

H3: Diduga Pelatihan dan Pengembangan Sumber Daya Manusia berpengaruh terhadap Prestasi Kerja.

\section{Tinjauan Pustaka}

\subsection{Pelatihan}

Menurut Widodo (2015:82), pelatihan merupakan serangkaian aktivitas individu dalam meningkatkan keahlian dan pengetahuan secara sistematis sehingga mampu memiliki kinerja yang profesional di bidangnya. Berdasarkan pengertian tersebut, pelatihan berarti suatu perubahan yang sistematis dari Knowledge, Skill, Attitude dan Behaviour yang terus mengalami peningkatan yang dimiliki oleh setiap karyawan dengan itu dapat mewujudkan sasaran yang ingin dicapai oleh suatu organisasi atau perusahaan dalam pemenuhan standar SDM yang diinginkan.

\subsection{Pengembangan SDM}

Pengembangan adalah suatu usaha untuk meningkatkan kemampuan teknis, teoritis, konseptual, dan moral karyawan sesuai dengan kebituhan pekerjaan/ jabatan melalui pendidikan dan latihan. Pendidikan meningkatkan keahlian teoritis, konseptual, dan moral karyawan, sedangkan latihan bertujuan untuk meningkatkan keterampilan teknis pelaksanaan pekerjaan karyawan, workshoop bagi karyawan dapat meningkatkat pengetahuan lebih lagi di luar perusahaan.

\subsection{Prestasi Kerja}

Menurut Rivai (2013:604), kinerja merupakan suatu istilah secara umum yang digunakan sebagian atau seluruh tindakan atau aktivitas dari suatu organisasi pada suatu periode dengan suatu referensi pada sejumlah standar seperti biaya masa lalu yang diproyeksikan dengan dasar efisiensi, pertanggungjawaban atau akuntabilitas manajemen dan semacamnya. Pengertian tersebut dapat di simpulkan bahwa kinerja karyawan sumber daya manusia adalah prestasi kerja atau hasil kerja baik kualitas maupun kuantitas yang dicapai SDM persatuan priode waktu dalam melaksanakan tugas kerjanya sesuai dengan tangung jawab yang di berikan padanya.

\section{Metodologi}

\subsection{Jenis Data}

Jenis data yang digunakan dalam penelitian ini adalah:

a) Data kualitatif, adalah data yang diperoleh dari wawancara, observasi dan kepustakaan. 
b) Data kuantitatif adalah data yang diperoleh dari kuesioner yang akan dibagikan dan berhubungan dengan, asalah yang akan diteliti.

\subsection{Populasi dan Sampel}

Populasi dalam penelitian ini adalah karyawan dari PT. Tanjung Enim Lestari Pulp and Paper Unit Chemical Plant berjumlah 33 karyawan. Sampel dalam penelitian ini meliputi karyawan tetap saja di PT. Tanjung Enim Lestari Pulp and Paper Unit Chemical Plant yang berjumlah 33 karyawan.

\subsection{Teknik Pengumpulan Data}

Metode pengumpulan data yang digunakan dalam penelitian ini adalah:
a) Wawancara
c) Observasi
b) Kuesioner
d) Dokumentasi

\section{Hasil dan Pembahasan}

\subsection{Pengujian Uji Validitas}

Uji Validitas dalam penelitian ini dilakukan untuk mengukur tepat atau tidak indikator atau kuesioner dari masing-masing variabel. Pengujian validitas ini dilakukan terhadap 61 responden, maka pengujian validitas data dengan mengunakan uji dua sisi dengan taraf signifikan 5\%. Pengujian validitas ini dilakukan terhadap 33 responden, maka rtabel $\mathrm{df}=\mathrm{n}-2$ dengan taraf signifikan $5 \%, \mathrm{df}=33-2=31$, maka rtabel $=0,355$.

Tabel 1. Validitas variabel pelatihan(X1)

\begin{tabular}{cccc}
\hline Pertanyaan & $r_{\text {hitung }}$ & rtabel & Keterangan \\
\hline PL_1 & 0,609 & 0,355 & Valid \\
PL_2 & 0,709 & 0,355 & Valid \\
PL_3 & 0,413 & 0,355 & Valid \\
PL_4 & 0,748 & 0,355 & Valid \\
PL_5 & 0,357 & 0,355 & Valid \\
PL_6 & 0,428 & 0,355 & Valid \\
PL_7 & 0,754 & 0,355 & Valid \\
PL_8 & 0,735 & 0,355 & Valid \\
PL_9 & 0,681 & 0,355 & Valid \\
PL_10 & 0,366 & 0,355 & Valid \\
\hline
\end{tabular}


Tabel 2. Validitas variabel pengembangan $\operatorname{SDM}(\mathrm{X} 2)$

\begin{tabular}{cccc}
\hline Pertanyaan & rhitung $_{\text {rabel }}$ & Keterangan \\
\hline PeSDM_1 & 0,841 & 0,355 & Valid \\
PeSDM_2 & 0,809 & 0,355 & Valid \\
PeSDM_3 & 0,813 & 0,355 & Valid \\
PeSDM_4 & 0,358 & 0,355 & Valid \\
PeSDM_5 & 0,631 & 0,355 & Valid \\
PeSDM_6 & 0,473 & 0,355 & Valid \\
PeSDM_7 & 0,832 & 0,355 & Valid \\
PeSDM_8 & 0,751 & 0,355 & Valid \\
PeSDM_9 & 0,737 & 0,355 & Valid \\
PeSDM_10 & 0,858 & 0,355 & Valid \\
\hline
\end{tabular}

Tabel 3. Validitas variabel prestasi kerja (Y)

\begin{tabular}{cccc}
\hline Pertanyaan & $r_{\text {hitung }}$ & $r_{\text {tabel }}$ & Keterangan \\
\hline PK_1 & 0,752 & 0,355 & Valid \\
PK_2 & 0,776 & 0,355 & Valid \\
PK_3 & 0,840 & 0,355 & Valid \\
PK_4 & 0,908 & 0,355 & Valid \\
PK_5 & 0,587 & 0,355 & Valid \\
PK_6 & 0,710 & 0,355 & Valid \\
PK_7 & 0,828 & 0,355 & Valid \\
PK_8 & 0,828 & 0,355 & Valid \\
PK_9 & 0,816 & 0,355 & Valid \\
PK_10 & 0,892 & 0,355 & Valid \\
\hline
\end{tabular}


Hasil uji validitas dari ke tiga variabel pada tabel 1,2, dan 3 menunjukan bahwa seluruh butir pernyataan valid, karena nilai r-hitung lebih besar dari r-tabel $(0,355)$.

\subsection{Hasil Uji Reliabilitas}

Pengujian reliabilitas dalam penelitian ini menggunakan Cronbach Alpha. Uji reliabilitas digunakan untuk mengukur suatu kuesioner yang merupakan indikator dari penelitian ini. Hasil pengujian reliabilitas dapat dilihat pada bagan di bawah ini:

Tabel 4. Hasil uji reliabilitas

\begin{tabular}{cccc}
\hline Variabel & Cronbachs Alpha & Standar Reliabilitas & Keterangan \\
\hline X1 & 0,710 & 0,60 & Reliabel \\
X2 & 0,834 & 0,60 & Reliabel \\
Y & 0,879 & 0,60 & Reliabel \\
\hline
\end{tabular}

Nilai Cronbachs Alpha semua variabel lebih dari 0,60 sehingga dapat disimpulkan bahwa indikator atau kuesioner dalam penelitian ini dikatakan reliabel dan dapat dipercaya sebagai alat ukur variabel.

\subsection{Analisis Regresi Linier Berganda}

Pada penelitian ini digunakan analisis regresi linier berganda untuk pembuktian hipotesis penelitian, analisis ini menggunakan input berdasarkan data yang diperoleh melalui kuesioner.

Tabel 5. Hasil analisis regresi berganda

\begin{tabular}{ccc}
\hline Model & Unstandardized Coefficients & $\mathrm{T}$ \\
\hline Constant & $-2,700$ &,- 370 \\
X1 &, 323 & 1,569 \\
X2 &, 702 & 3,702 \\
\hline
\end{tabular}

Dari hasil tersebut dapat disimpulkan bahwa persamaan regresi yang diperoleh adalah sebagai berikut:

$$
\mathrm{Y}=-2,700+0,323 X_{1}+0,702 X_{2}
$$

Persamaan regresi tersebut dapat dijelaskan dalam Bahasa yang sederhana dan mudah dipahami sebagaimana berikut:

1. Nilai konstanta sebesar $-2,700$ berarti jika variabel Pelatihan dan Pengembangan SDM bernilai nol, maka Prestasi Kerja akan bernilai sebesar -2,700. Sehingga dapat di simpulkan bahwa tanpa ada variabel Pelatihan, dan Pengembangan SDM maka Prestasi Kerja akan sebesar -2,700 dan menunjukan hasil yang negatif.

2.Variabel Pelatihan mempengaruhi Prestasi Kerja sebesar 0,323 atau berpengaruh secara positif. 
3.Variabel Pengembangan SDM mempengaruhi Prestasi Kerja sebesar 0,702 atau berpengaruh secara positif.

\subsection{Uji-t}

Uji t bertujuan untuk menunjukan hasil berapa besar pengaru satu variabel independen secara individual dalam menjelaskan perbedaan antara dua nilai rata-rata dengan standar error dari perbedaan rata-rata dua sampel (Ghozali 2013:98-99)

Tabel 6. Hasil uji t variabel pelatihan (X1)

\begin{tabular}{cccc}
\hline Model & Unstandardized Coefficients & T & Sig \\
\hline Constant & 7,146 & 0,885 & 0,383 \\
X1 & 0,818 & 4,408 & 0,000 \\
\hline
\end{tabular}

Berdasarkan pengujian, diketahui bahwa nilai t hitung pada variabel promosi jabatan lebih besar dari $t$ tabel ( $t$ hitung 4,408 $>\mathrm{t}$ tabel 2,042). Hal tersebut menunjukan bahwa H1 diterima dan pelatihan berpengaruh secara signifikan terhadap Prestasi Kerja.

Tabel 7. Hasil uji t variabel pengembangan SDM (X2)

\begin{tabular}{cccc}
\hline Model & Unstandardized Coefficients & $\mathrm{T}$ & Sig \\
\hline Constant & 2,654 & 0,402 & 0,691 \\
X2 & 0,895 & 6,075 & 0,000 \\
\hline
\end{tabular}

Berdasarkan pengujian, diketahui bahwa nilai t hitung pada variabel mutasi jabatan lebih besar dari t tabel (t hitung 6,075 > t tabel 2,042). Hal tersebut menunjukan bahwa H2 diterima dan pengembangan sdm berpengaruh secara signifikan terhadap Prestasi Kerja.

\section{$4.5 U j i-F$}

Uji F menunjukan semua variabel independen atau bebas yang dimasukan dalam model regresi mempunyai pengaruh secara bersama-sama terhadap variabel dependen untuk mengambil keputusan hipotesis diterima atau ditolak.

Tabel 8. Hasil uji F

\begin{tabular}{cccccc}
\hline Model & $\begin{array}{c}\text { Sum of } \\
\text { Squares }\end{array}$ & Df & $\begin{array}{c}\text { Mean } \\
\text { Square }\end{array}$ & F & Sig \\
\hline Regression & 611,633 & 2 & 305,816 & 20,551 &, $000^{\text {a }}$ \\
Residual & 446,428 & 30 & 14,881 & & \\
Total & 1058,061 & 32 & & & \\
\hline
\end{tabular}

Berdasarkan pengujian diketahui bahwa nilai $\mathrm{F}$ hitung lebih besar dari $\mathrm{F}$ tabel (F hitung 20,551 $>\mathrm{F}$ tabel 3,32). Hal tersebut menunjukan bahwa pelatihan dan pengembangan sdm berpengaruh secara simultan dan signifikan terhadap Prestasi Kerja. 


\subsection{Hasil Uji Koefisien Determinasi $\left(R^{2}\right)$}

Koefisien determinasi digunakan untuk mengetahui seberapa besarnya persentase keeratan antar variabel terhadap variabel dependen.

Tabel 11. Hasil uji koefisien determinasi $\left(\mathrm{R}^{2}\right)$

\begin{tabular}{ccccc}
\hline Model & $\mathrm{R}$ & $\mathrm{R}$ Square & $\begin{array}{c}\text { Adjusted R } \\
\text { Square }\end{array}$ & $\begin{array}{c}\text { Std.Error of the } \\
\text { Estimate }\end{array}$ \\
\hline 1 &, $760^{\mathrm{a}}$ &, 578 &, 550 & 3,858 \\
\hline
\end{tabular}

Berdasarkan hasil analisis dapat diketahui nilai Adjusted R2 sebesar 0,578 atau 57,8\% menunjukkan bahwa variabel prestasi kerja yang dapat dijelaskan oleh pelatihan dan pengembangan SDM adalah 57,8\%, sedangkan sisanya 0,422 atau $42,2 \%$ dijelaskan oleh faktor-faktor lain yang tidak disertakan dalam penelitian ini.

\section{Kesimpulan}

Berdasarkan data yang didapatkan setelah diolah kembali, maka hasil penelitian tentang pengaruh Pelatihan dan Pengembangan SDM terhadap Prestasi Kerja pada PT. Tanjung Enim Lestari Pulp and Paper Unit Chemical Plant, dapat ditarik kesimpulan sebagai berikut:

1. Pelatihan mempunyai pengaruh positif dan signifikan diketahui nilai Sig untuk pengaruh Pelatihan (X1) terhadap Prestasi Kerja (Y) adalah sebesar 0,00>0,05 dan Nilai t hitung 4,408 > 2,042, sehingga dapat disimpulkan bahwa Ho ditolak H1 diterima yang berarti terdapat pengaruh Pelatihan (X1) terhadap Prestasi Kerja (Y).

2. Pengembangan SDM mempunyai pengaruh positif dan signifikan Diketahui nilai Sig untuk pengaruh Pengembangan SDM (X2) terhadap Prestasi Kerja (Y) adalah sebesar 0,00<0,05 dan Nilai t hitung 6,075 > 2,042, sehingga dapat disimpulkan bahwa Ho ditolak H1 diterima yang berarti terdapat pengaruh Pengembangan SDM (X2) terhadap Prestasi Kerja (Y).

3. Pengujian secara bersama-sama antara variabel Pelatihan dan Pengembangan SDM terhadap Prestasi Kerja memiliki nilai fhitung sebesar 20,551 dan signifikansi sebesar 0,000. Karena tingkat signifikansi adalah $0,000(0,000<0,05)$ maka hipotesis diterima.

4. Pelatihan dan Pengembangan berpengaruh secara positif dan signifikan terhadap Prestasi Kerja pada PT. Tanjung Enim Lestari Pulp and Paper Unit Chemical Plant.

5. Dari hasil uji koefisien determinasi (R2) diperoleh nilai Adjusted R2 sebesar 0,578 atau $57,8 \%$ menunjukkan bahwa variabel prestasi kerja yang dapat dijelaskan oleh pelatihan dan pengembangan SDM adalah 57,8\%, sedangkan sisanya 0,442 atau 44,2\% dijelaskan oleh faktor-faktor lain yang tidak disertakan dalam penelitian ini

Berdasarkan simpulan yang telah diperoleh dari hasil penelitian ini, maka ada beberapa saran yang penulis berikan yaitu antara lain:

1. PT. Tanjung Enim Lestari Pulp and Paper Unit Chemical Plant harus terus meningkatkan Prestasi kerja dengan memberikan pelatihan secara berkala. Seperti on the job training dan off the job training melalui Lembaga konsultan SDM.

2. PT. Tanjung Enim Lestari Pulp and Paper Unit Chemical Plant harus terus meningkatkan 
Prestasi Kerja dengan melakukan pelatihan dan pengembangan karyawan yang baik. Secara transparan kepada karyawan yang mengikuti pelatihan, agar karyawan yang kurang berkompetensi diwajibkan untuk mengikuti program pelatihan kembali.

3. Prestasi Kerja yang telah dicapai saat ini hendaknya harus terus dipertahankan dan lebih ditingkatkan, dengan cara meningkatkan kompetensi dan komitmen karyawan agar tercapai hasil yang diinginkan PT. Tanjung Enim Lestari Pulp and Paper Unit Chemical Plant

4. Perusahaan menempatkan karyawan yang memiliki kompetensi dan bidang yang sesuai, seperti pihak perusahaan dapat melaksanakan pelatihan dan pengembangan karyawan dengan penuh tanggung jawab agar tercapai prestasi kerja karyawan yang kompeten dan berkualitas.

5. PT. Tanjung Enim Lestari Pulp and Paper Unit Chemical Plant harus memberikan pelatihan kompetensi terhadap karyawan. Untuk meningkatkan keterampilan,skill, kemampaun, dan kecakapan.

6. Untuk peneliti selanjutnya diharapkan untuk meneliti variabel-variabel lain yang tidak termasuk di penelitian ini, seperti lingkungan kerja, gaya kepemimpinan, budaya organisasi, motivasi kerja dan lainnya.

\section{Referensi}

Ghozali, Imam. 2011. “Aplikasi Analisis Multivariate Dengan Program SPSS”.Semarang: Badan Penerbit Universitas Diponegoro.

Goyena, R. (2019). Kajian Pustaka, Kerangka Pemikiran, dan Hipotesis. Journal of Chemical Information and Modeling, https://doi.org/10.1017/CBO9781107415324.004

Indra Wardhana, A. D. S. (2015). Pengaruh Motivasi, Insentif, dan Pengembangan Karir Terhadap Kinerja Karyawan PT. Telkomsel Grapari Pemuda Surabaya. https://jurnal.narotama.ac.id/index.php/magistra/article/view/105

Karir, P., Putu, N., Sumadewi, A., \& Suwandana, G. M. (2017). Pengaruh Pengalaman Kerja, Prestasi Kerja. https://ojs.unud.ac.id/index.php/Manajemen/article/view/45790

Kristola, D., Ayu, I. G., \& Adnyani, D. (n.d.). Terhadap Prestasi Kerja Serta Dampaknya Terhadap Pengembangan Karir Pegawai Di Balai Karantina Pertanian Kelas 1 Denpasar. https://media.neliti.com/media/publications/250885-pengaruh-diklat-dan-pengalaman-kerjater-5fa5fb98

Kurniawan, F. A., Musadieq, M. Al, \& Prasetya, A. (2015). Pengaruh Pendidikan dan Pelatihan Terhadap Kemampuan dan Kinerja Karyawan (Studi Pada PT. PLN (Persero) Area Malang). Jurnal Administrasi Bisnis.

http://administrasibisnis.studentjournal.ub.ac.id/index.php/jab/article/view/1040

Kusuma, G. C., Musadieq, M. Al, Nurtjahjono, G. E., Administrasi, F. I., \& Brawijaya, U. (2018). Pengaruh Motivasi Dan Pelatihan Terhadap Kinerja Karyawan. Economica, https://doi.org/10.22202/economica.2018.v7.i1.1873

Lagale, D. G. (2014). Pelatihan, Disiplin Kerja dan Kualitas Kerja Terhadap Prestasi Kerja pada PT. PLN (PERSERO) Area Manado. Jurnal Emba. https://ejournal.unsrat.ac.id/index.php/emba/article/view/4440 
Mandiangan, E., \& Rahyuda, A. (2015). Pengaruh Prestasi Kerja, Senioritas, Dan Loyalitas Terhadap Promosi Jabatan Pada Discovery Kartika Plaza Hotel Bali. E-Jurnal Manajemen Universitas Udayana. https://ojs.unud.ac.id/index.php/Manajemen/article/view/11815

M. Hutajulu, S., \& Supriyanto. (2013). Tinjauan Pelaksanaan Pelatihan dan Pengembangan Karyawan pada PT. Inalum Kabupaten Batubara. Jurnal Bisnis Administrasi. Retrieved from https://ejurnal.plm.ac.id/index.php/BIS-A/article/view/114/96

Mandey, S., \& Sahangggamu, P. (2014). Pengaruh Pelatihan Kerja, Motivasi, Dan Disiplin Kerja Terhadap Kinerja Karyawan Pada Pt. Bank Perkreditan Rakyat Dana Raya. Jurnal Riset Ekonomi, Manajemen, Bisnis dan Akuntansi. https://ejournal.unsrat.ac.id/index.php/emba/article/view/6359

Muamarizal, S., Dr. Samsir, SE., M. S., \& Marzolina, SE, M. (2015). Pengaruh Pengalaman Kerja Dan Penilaian Prestasi Kerja Terhadap Pengembangan Karir Karyawan pada PT. Jasaraharja Putera Cabang Pekanbaru. 2015. Retrieved from http://weekly.cnbnews.com/news/article.html?no=124000

Nabilah, F. P., Tewal, B., \& Trang, I. (2017). Pengaruh Pelatihan, Pendidika dan Iklim Organisasi Terhadap Kepuasan Kerja Karyawan Pada PT. PLN (Persero) Sektor Pembangkitan

Minahasa.

https://ejournal.unsrat.ac.id/index.php/emba/article/view/16460/15954

Pareraway, A. S., Kojo, C., \& Roring, F. (2018). Pengaruh Lingkungan Kerja, Pelatihan, dan Pemberdayaan SDM Terhadap Kepuasan Kerja Karyawan PT. PLN (PERSERO) Wilayah Suluttenggo. https://ejournal.unsrat.ac.id/index.php/emba/article/view/20665

Pratama Putra, I., \& Yuniari, M. (2013). Pengaruh Pendidikan dan Pelatihan Terhadap Prestasi Kerja Karyawan Bagian Fixed Phone Sales pada PT.Telekomunikasi.Tbk Denpasar. E-Jurnal Manajemen Universitas Udayana.

https://ojs.unud.ac.id/index.php/Manajemen/article/view/5407

Ratnasari, S. (2013). Pengaruh Faktor-Faktor Pelatihan Terhadap Prestasi Kerja Karyawan Departemen Produksi Pt. X Batam. Buletin Studi Ekonomi. https://ojs.unud.ac.id/index.php/bse/article/view/6157/4642

Repi, J. V. P. C. K. A. L. (n.d.). Pengaruh motivasi kerja, disiplin kerja, dan kepemimpinan terhadap prestasi kerja pegawai di badan perpustakaan provinsi sulawesi utara. https://ejournal.unsrat.ac.id/index.php/emba/article/view/11663

Savitri, D. (2015). Pengaruh Pelatihan Terhadap Prestasi Lembuswana Di Samarinda. https://ejournal.adbisnis.fisip-unmul.ac.id/site/?p=1196

Sujarweni, V. Wiratna. 2014. Metode Penelitian: Lengkap, Praktis, dan Mudah Dipahami. Yogyakarta: Pustaka Baru Press.

Sugiyono. (2012). Metode Penelitian Pendidikan Pendekatan Kuantitatif, Kualitatif, dan R\&D. Bandung: Alfabeta.

Sukarjati, E., Minarsih, M. M., Warso, M. M., Jurusan, M., Fakultas, M., Dan, E., Jurusan, D. (2016). Pengaruh Kepemimpinan, Pengembangan Sumber Daya Manusia dan Kepuasan Kerja Terhadap Kinerja Pegawai. Journal of Management. https://jurnal.unpand.ac.id/index.php/MS/article/view/411 